\title{
GENETIC AND ENDOCRINE STUDIES OF THE PREGNANCY-BLOCKING PHEROMONE OF MICE
}

\author{
P. G. HOPPE \\ The Jackson Laboratory, Bar Harbor, Maine 04609, U.S.A.
}

(Received 24th December 1974)

Summary. Secretion of the pregnancy-blocking pheromone was stimulated by injection of depo-testosterone cypionate into females and males of inbred strains of mice which do not normally secrete the pheromone. Testosterone treatment of SJL males altered pheromone secretion so that pregnancies were blocked when the stud male was of the same inbred strain; an event that does not normally occur. Injection of epiandrosterone, androstenedione, androsterone or testosterone significantly increased pheromone secretion in SJL females, but progesterone and dehydroepiandrosterone were ineffective. Kidney weights were significantly increased by administration of androgen metabolites and the possibility of the kidney being the site of pheromone synthesis is discussed. The preputial gland can be excluded as the site of pheromone synthesis since males which are hemizygous for the Tabby-J gene and have no preputial glands blocked pregnancies as effectively as their normal littermates. Preliminary results are also presented concerning the isolation of the pregnancy-blocking pheromone from urine. Urine was analysed by gas chromatography and a peak was observed whose concentration could be correlated with secretion of the pheromone, although the compound(s) has not been identified or tested for biological activity.

\section{INTRODUCTION}

Implantation failure frequently occurs when recently mated female mice are exposed to males of a strain different from that of the stud males (Bruce, 1960a, b), while exposure to males of the same strain as the stud males does not prevent implantation. Pregnancy block results from the presence of a primer pheromone in the urine of males (Parkes \& Bruce, 1961). Castration renders the male incapable of secreting the pheromone (Bruce, 1965) and strain differences exist in the ability of males to block implantation (Chapman \& Whitten, 1969). Spayed CBA females treated with androgen prevented implantation as effectively as normal CBA males and it has been concluded that secretion of the pregnancy-blocking pheromone is androgen-dependent (Dominic, 1965).

The present report describes the results of further studies of the effects of androgens, sex, and genotype on the secretion of the pregnancy-blocking pheromone, and attempts to isolate the pheromone are described. 


\section{MATERIALS AND METHODS}

Animals

All mice used in the present study were bred in the research colonies of the Jackson Laboratory. Adult males and females of the SJL/J, BALB/cWt, and C57BL/10Wt inbred strains were used. These strains were chosen because Chapman \& Whitten (1969) reported that the SJL and BALB/c males produced the pregnancy-blocking pheromone ('capable' males) while the $\mathrm{BL} / 10$ males did not ('incapable' males). We also determined whether the preputial gland was required for secretion of the pregnancy-blocking pheromone by testing $129 / \mathrm{Sv}$ males that are hemizygous for the Tabby-J locus and resemble Tabby mice in that they are deficient in preputial glands (Grüneberg, 1971).

Evidence for pheromone secretion was obtained by observing the number of blocked pregnancies in recently mated females of the SJL or BALB/c strains. Pro-oestrous females were selected by the external appearance of the vagina (Champlin, Dorr \& Gates, 1973), and mated to fertile BALB/c or SJL males. Twenty-four hours after the appearance of a vaginal plug (Day 2), females were transferred to cages containing a mouse which was to be tested for pheromone secretion. Females were undisturbed until they were killed on Day 8 and examined for evidence of implantation failure. Data were analysed by analysis of variance and Student-Newman-Keuls multiple range test (Steele \& Torrie, 1960).

\section{RESULTS}

Effects of strain and sex upon pheromone induction by testosterone

Depo-testosterone cypionate $(100 \mathrm{mg} / \mathrm{ml}$ in cottonseed oil; Upjohn Co.) was injected into intact males and females of a capable strain (SJL) and an incapable strain (BL/10) to observe the effect of androgens on secretion of the pregnancy-blocking pheromone in mice differing with respect to sex and genotype. The first injection of $20 \mathrm{mg}$ depo-testosterone cypionate was followed by weekly injections of $10 \mathrm{mg}$. Treated mice were tested for pheromone secretion after the fourth injection.

The administration of depo-testosterone cypionate to either males or females of 'capable' and 'incapable' strains resulted in a significant $(P<0 \cdot 01)$ number of blocked pregnancies when compared to uninjected controls (Table 1). The effectiveness of the pheromone secreted by SJL males was altered by testosterone treatment, and pheromone secretion was stimulated in males and females of the 'incapable' strain, $\mathrm{BL} / 10$.

\section{Relative potencies of various androgens on pheromone secretion}

Various androgen metabolites and progesterone (Sigma) were injected at a dose of $1 \mathrm{mg} /$ day into intact SJL females to determine whether a specific androgen structure is required for pheromone secretion. After 1 week of injections, the females were tested for pheromone secretion during the following 2 weeks. They were killed $24 \mathrm{hr}$ after the twentieth injection and body, preputial gland, and kidney weights were recorded. There were no differences in body weight but preputial gland and kidney weights were significantly $(P<0.05)$ 
Table 1. Effect of testosterone cypionate on secretion of the pregnancy-blocking pheromone by male and female mice

\begin{tabular}{|c|c|c|}
\hline Treatment and strain tested* & $\begin{array}{c}\text { pre } \\
\mathcal{N} o .\end{array}$ & $\%$ \\
\hline $\begin{array}{l}\text { Left with stud } \\
\text { SJL o } \\
\text { SJL } 0 \text { + testosterone } \\
\text { SJL \&+ testosterone } \\
\text { C57BL/10 } 0 \\
\text { C57BL } / 10 \text { d + testosterone } \\
\text { C57BL/10 o+ testosterone }\end{array}$ & $\begin{array}{l}1 / 15 \\
4 / 14 \\
7 / 10 \\
8 / 10 \\
2 / 11 \\
8 / 10 \\
6 / 10\end{array}$ & $\begin{array}{r}7 \\
28 \\
70 \\
80 \\
18 \\
80 \\
60\end{array}$ \\
\hline
\end{tabular}

* BALB/c females were mated to SJL males and exposed to test animals $24 \mathrm{hr}$ after the occurrence of a vaginal plug.

increased by androstenedione, androsterone and testosterone compared to those of the oil-injected controls (Table 2). Dehydroepiandrosterone and epiandrosterone treatment did not affect kidney weight but caused a significant increase in preputial gland weight. Treatment with progesterone suppressed preputial and kidney weights but not significantly $(P>0.05)$ below those of controls injected with oil. The proportion of pregnancies blocked was significantly increased $(P<0.01)$ by the injection of epiandrosterone, androstenedione, androsterone, and testosterone. Dehydroepiandrosterone increased the proportion of pregnancies blocked but the value was not significantly $(P>0.05)$ different from that found in the control mice.

Table 2. Effect of androgens and progesterone on secretion of the pregnancyblocking pheromone by SJL female mice

\begin{tabular}{|c|c|c|c|c|c|}
\hline Treatment $\dagger$ & $\begin{array}{l}\text { No. of } \\
\text { mice }\end{array}$ & $\begin{array}{c}\text { Body } \\
\text { wt }(g)\end{array}$ & $\begin{array}{c}\text { Preputial } \\
\text { gland } \\
w t(m g)\end{array}$ & $\begin{array}{c}\text { Kidney } w t \\
\quad(m g)\end{array}$ & $\begin{array}{c}\text { Proportion of } \\
\text { blocked } \\
\text { pregnancies } \\
(\%) \ddagger\end{array}$ \\
\hline $\begin{array}{l}\text { Sesame oil } \\
\text { Progesterone } \\
\text { Dehydroepiandrosterone } \\
\text { Epiandrosterone } \\
\text { Androstenedione } \\
\text { Androsterone } \\
\text { Testosterone }\end{array}$ & $\begin{array}{r}10 \\
9 \\
10 \\
10 \\
9 \\
10 \\
10\end{array}$ & $\begin{array}{l}23.1 \pm 0 \cdot 3 \\
24 \cdot 8 \pm 0 \cdot 7 \\
24 \cdot 4 \pm 0 \cdot 3 \\
23 \cdot 6 \pm 0 \cdot 4 \\
23 \cdot 3 \pm 0 \cdot 3 \\
23 \cdot 2 \pm 0 \cdot 4 \\
24 \cdot 7 \pm 0 \cdot 4\end{array}$ & $\begin{array}{l}20 \cdot 4 \pm 2 \cdot 0^{\mathrm{a}} \\
16 \cdot 9 \pm 2 \cdot 2^{\mathrm{a}} \\
42 \cdot 0 \pm 2 \cdot 6^{\mathrm{b}} \\
51 \cdot 8 \pm 4 \cdot 7^{\mathrm{b}} \\
69 \cdot 7 \pm 4 \cdot 9^{\mathrm{c}} \\
77 \cdot 8 \pm 4 \cdot 3^{\mathrm{cd}} \\
91 \cdot 2 \pm 4 \cdot 1^{\mathrm{cd}}\end{array}$ & $\begin{array}{l}321 \cdot 8 \pm 6 \cdot 5^{\mathrm{a}} \\
305 \cdot 1 \pm 9 \cdot 3^{\mathrm{ab}} \\
340 \cdot 7 \pm 6 \cdot 0^{\mathrm{abc}} \\
350 \cdot 0 \pm 11 \cdot 8^{\mathrm{abc}} \\
390 \cdot 2 \pm 4 \cdot 1^{\mathrm{c}} \\
359 \cdot 4 \pm 8 \cdot 5^{\mathrm{bc}} \\
468 \cdot 0 \pm 24 \cdot 0^{\mathrm{d}}\end{array}$ & $\begin{array}{r}1 / 19(5 \cdot 4) \\
2 / 10(20 \cdot 0) \\
5 / 10(58 \cdot 0) \\
8 / 10(80 \cdot 0)^{*} \\
14 / 18(77 \cdot 8)^{*} \\
17 / 19(89 \cdot 5)^{*} \\
16 / 17(94 \cdot 1)^{*}\end{array}$ \\
\hline
\end{tabular}

Means ( \pm S.E.) with the same superscript are not significantly different $(P>0.05)$.

* Significantly different from control $(P<0.01)$.

$\dagger$ Daily subcutaneous injection of $1 \mathrm{mg}$ steroid in $0.1 \mathrm{ml}$ sesame oil.

$\ddagger$ Number of recently mated BALB/c females paired with treated animals.

\section{Role of preputial glands on pheromone secretion}

Hemizygous Tabby-J males $\left(129 / \mathrm{Sv} T a^{\mathrm{J}} / \mathrm{Y}\right)$ were as effective as normal littermate males $(129 / \mathrm{Sv} \mathrm{X} / \mathrm{Y})$ in blocking pregnancy in $\mathrm{BALB} / \mathrm{c}$ females mated with $\mathrm{BALB} / \mathrm{c}$ males $(7 / 10(70 \%)$ pregnancies blocked versus $9 / 13(69 \%)$, respectively). 
Fractionation of urine for pheromone activity

Females of the BALB/c strain were mated to SJL males and used to test various extracts of $\mathrm{BALB} / \mathrm{c}$ male urine. The extracts (1-ml aliquots) were placed in glass scintillation vials in which a 13-mm hole had been bored through the cap and a $2 \cdot 5-\mathrm{cm}$ piece of glass tubing inserted. Exposure of mated females to the extracts commenced on Day 2 and vials were replaced every $12 \mathrm{hr}$. In preliminary trials, pregnancies were blocked as effectively by vials containing whole urine as by the presence of the donor males.

Procedures used initially to try to isolate the pregnancy-blocking pheromone were steam distillation, organic solvent extraction, thin-layer chromatography and vacuum sublimation. All these procedures resulted in loss of the pheromone or in its destruction since no pregnancy-blocking activity could be measured in the respective extracts.

When nitrogen was bubbled into urine by means of a capillary tube and the vapour was condensed in a U-tube immersed in dry ice and acetone, the condensate was found to have pregnancy-blocking activity. A large quantity of

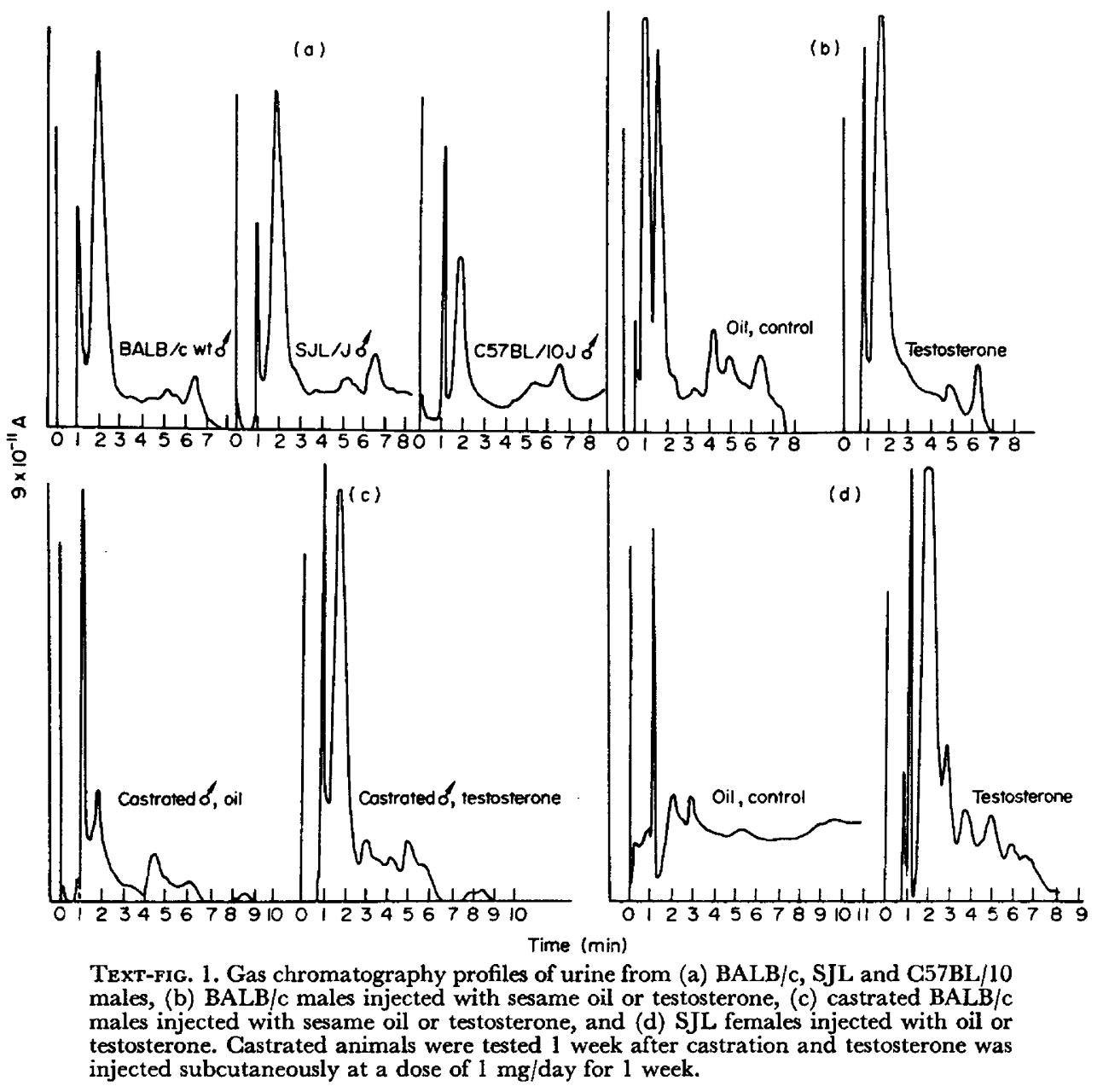


water condensed in the U-tube and it was not possible to concentrate the pheromone greatly, although it was separated from numerous other substances present in the urine. Freeze-drying of the condensate resulted in loss of pheromone activity.

Gas chromatography of urine was accomplished by injecting whole urine onto a $6 \mathrm{~mm}$ (i.d.) $\times 6 \mathrm{ft}$ glass column packed with $20 \%$ ethylene glycol glutarate on Anakrom 110/120 ABS. A Barber-Coleman gas-chromatograph equipped with an $\mathrm{H}_{2}$ flame ionization detector was used. Column temperature was maintained at $150^{\circ} \mathrm{C}$ and the injector and detector at $175^{\circ} \mathrm{C}$. The $\mathrm{N}_{2}, \mathrm{H}_{2}$, and air pressures were 11,26 , and $50 \mathrm{lbf} / \mathrm{in}^{2}$, respectively. Urine samples (5 $\mu$ litres) from intact and castrated 'capable' males (tested 1 week after castration), 'incapable' males, females, and testosterone-injected ( $1 \mathrm{mg} /$ day for 1 week) intact and castrated males were chromatographed.

As shown in Text-fig. 1(a), a component with a retention time of $1.8 \mathrm{~min}$ was more concentrated in urine from $\mathrm{BALB} / \mathrm{c}$ and $\mathrm{SJL}$ males than in urine of 'incapable' BL/10 males. Testosterone increased the concentration of this component when injected into intact BALB/c males (Text-fig. $1 \mathrm{~b}$ ). Castration of $\mathrm{BALB} / \mathrm{c}$ males decreased its concentration and testosterone treatment restored it (Text-fig. 1c). The concentration of the component with a retention time of $1.8 \mathrm{~min}$ in SJL female urine was similar to that in castrated male urine. Administration of testosterone to SJL females increased concentration of the component to a level similar to that observed in urine from testosterone-treated castrated males (Text-fig. 1d). Thus, a low molecular weight compound(s) was found to be more concentrated in urine of 'capable' males than of 'incapable' males. The concentration of the compound was increased by giving testosterone to intact and castrated males as well as intact females.

\section{DISCUSSION}

Secretion of the pregnancy-blocking pheromone can be stimulated by the administration of androgens to females and males which normally do not secrete the pheromone. The ability of a male of a particular genotype to secrete this pheromone may be dependent on the endogenous level of circulating androgens. The means by which female mice discriminate between males of different pheromone-secreting strains is not known. Whitten (1966) suggested that strain differences were due to the secretion of an 'identifier' substance, while Parkes (1960) proposed that the pheromone consisted of a spectrum of odorous compounds which were secreted in dissimilar proportions by males of different strains. Since testosterone-treated SJL males blocked pregnancies when the stud males were also of the SJL strain, it seems unlikely that testosterone treatment of the alien male of the same strain as the stud male would alter the secretion of the compound(s) that confers strain distinction, but rather that the females discriminated between the SJL males on the basis of the concentration of pheromone in their urine. It is possible that assay of serum androgen levels in males of a number of inbred strains might indicate significant differences in androgen levels that could be correlated with secretion of the pregnancy-blocking pheromone and differences in pheromone concentration in urine. 
Structural specificity of androgens was not observed in the present study and progesterone was ineffective in stimulating pheromone secretion, but studies of a wider variety of androgens may reveal a greater degree of structural specificity than is now evident.

The site of synthesis of the pregnancy-blocking pheromone is not known. In the present study, androgen administration stimulated secretion of the pheromone and increased preputial gland and kidney weights in females. The involvement of the preputial gland in pheromone synthesis can be excluded since preputialectomized males (W. K. Whitten, unpublished data) and Tabby-J males, which, like Tabby males (Grüneberg, 1971), lack preputial glands, secrete the pregnancy-blocking pheromone. A possible site for pheromone synthesis could be the parietal epithelium of the Bowman's capsule. Crabtree (1940) reported that a cuboidal type of epithelium was increased in males at the time of sexual maturity while females retained a squamous type. Kidneys of males are heavier than those of females (Dickie, 1958) and kidney weight is increased by androgen treatment (Kochakian, 1944). Several enzymes in the mouse kidney are known to be induced by testosterone administration (Shaw \& Koen, 1963; Dofuku, Tettenborn \& Ohno, 1971). Although based on indirect evidence, I suggest that the kidney is involved in pheromone synthesis under the influence of androgens. Confirmation of this hypothesis may depend upon the isolation and characterization of the pregnancy-blocking pheromone of the mouse.

Attempts to concentrate and isolate the pregnancy-blocking pheromone resulted in some information that may be useful in further studies. Gas chromatography of urine on an ethylene glycol glutarate column indicated the presence of a component, the concentration of which can be correlated with pheromone activity in 'capable' and 'incapable' strains and with administration of testosterone to castrated males or females. We are attempting to test the biological activity of this peak but have met with difficulty because of the lengthy exposure period (approximately $48 \mathrm{hr}$ ) required and the large quantity of urine necessary for the biological assay. The possibility of using the radioimmunoassay for gonadotrophins to develop a more sensitive pheromone assay is under investigation.

\section{ACKNOWLEDGMENTS}

This work was supported by NIH Grant HD 04083 from the National Institute of Child Health and Human Development, and by an allocation from NIH General Research Support Grant RR 05545 from the Division of Research Resources to the Jackson Laboratory. The author expresses gratitude to $\mathrm{Dr}$ W. K. Whitten for his interest and criticism, and to Dr A. A. Kandutsch for assistance in preparation of the manuscript.

The Jackson Laboratory is fully accredited by the American Association for Accreditation of Laboratory Animal Care.

\section{REFERENGES}

Bruce, H. M. (1960a) A block to pregnancy in the mouse caused by proximity of strange males. $\mathcal{F}$. Reprod. Fert. 1, 96-103. 
BRUCE, H. M. (1960b) Further observations on pregnancy block in mice caused by the proximity of strange males. 7. Reprod. Fert. 1, 311-312.

BRUGE, H. M. (1965) Effect of castration on the reproductive pheromones of male mice. 7. Reprod. Fert. 10, 141-143.

Champlin, A. K., Dorr, D. L. \& Gates, A. H. (1973) Determining the stage of the estrous cycle in the mouse by the appearance of the vagina. Biol. Reprod. 8, 491-494.

Chapman, V. M. \& Whitten, W. K. (1969) The occurrence and inheritance of pregnancy block in inbred mice. Genetics, Princeton, 61, S9, Abstr.

CRABtree, C. (1940) Sex difference in the structure of Bowman's capsule in the mouse. Science, N.r. 91, 299.

Dickie, M. M. (1958) Adrenal tumours and other pathological changes in reciprocal backcross mice. I. Backcrosses to strain CE. Ph.D. thesis, Brown University, Providence, R.I.

Dofuku, R., Tettenborn, V. \& Ohno, S. (1971) Testosterone-"Regulon" in the mouse kidney. Nature, Lond. 232, 5-7.

Dominıc, G. J. (1965) The origin of the pheromones causing pregnancy block in mice. 7. Reprod. Fert. 10, $469-472$.

GRÜNEBERG, H. (1971) The glandular aspects of the tabby syndrome in the mouse. F. Embryol. exp. Morph. 25, 1-19.

KOCHAKYAN, C. D. (1944) A comparison of the renotrophic with the androgenic activity of various steroids. Am. F. Physiol. 142, 315-325.

Parkes, A. S. (1960) The role of odorous substances in mammalian reproduction. F. Reprod. Fert. 1, 312-314.

Parkes, A. S. \& Bruce, H. M. (1961) Olfactory stimuli in mammalian reproduction. Science, N. Y. 134, 1049-1054.

Shaw, G. R. \& Koen, A. L. (1963) Hormone-induced esterase in mouse kidney. Science, N.Y. 140, $70-71$.

Steel, R. G. D. \& Torrie, J. H. (1960) Principles and Procedures of Statistics, p. 322. McGraw-Hill, New York.

Whitten, W. K. (1966) Pheromones and mammalian reproduction. Adv. Reprod. Physiol. 1, 155-180. 